\title{
Challenges in Developing Virtual Reality, Augmented Reality and Mixed-Reality Applications: Case Studies on A 3D-Based Tangible Cultural Heritage Conservation
}

\author{
Ahmad Zainul Fanani ${ }^{1}$, Khafiizh Hastuti ${ }^{2}$, Arry Maulana Syarif ${ }^{3}$, Prayanto Widyo Harsanto ${ }^{4}$ \\ Faculty of Computer Science, Universitas Dian Nuswantoro, Semarang, Indonesia ${ }^{1,2,3}$ \\ Faculty of Visual Communication Design, Institut Seni Rupa Indonesia Yogyakarta, Yogyakarta, Indonesia ${ }^{4}$
}

\begin{abstract}
A model that contributes in a simple, practical and effective way to develop 3D-based $\mathrm{CH}$ conservation applications involving the use of VR, AR and MR technologies was proposed based on the identification of challenges in developing applications. Identification was carried out by analyzing related and relevant articles selected randomly using Google and Google Scholar search engines. The model can prevent researchers from lack of planning in carrying out research in this field, and it is suitable for those just starting out with this type of research. In addition, this model can support researchers to more easily, practically and effectively implement 3D-based cultural heritage conservation by using virtual reality or augmented reality or mixed reality technology.
\end{abstract}

Keywords-Virtual reality; augmented reality; mixed reality; tangible cultural heritage; 3D-based cultural heritage conservation

\section{INTRODUCTION}

This article aims to study the use of virtual reality (VR), augmented reality (AR) and combination of VR and AR called mixed reality (MR) for the conservation of tangible cultural heritage in order to identify challenges in developing 3Dbased tangible cultural heritage $(\mathrm{CH})$ conservation. Tangible cultural heritage objects were focused on immovable objects such as building and historic places. Moving objects are also included in the discussion but in a small portion. Challenges were classified according to tasks in the development which were summarized based on cases found in related and relevant research articles. The identification results are then used to design a model for developing cultural heritage-VR (CH-VR), cultural heritage-AR (CH-AR) or cultural heritage-MR $(\mathrm{CH}-$ MR) applications. The model contributes in simply and practically way in determining a suitable method for developing 3D-based $\mathrm{CH}$ conservation applications using VR, AR or MR. Along with the development of this type of research which is increasingly rapid, the proposed model can prevent researchers who just starting out with this type of research from lack of planning in carrying out researches in this field. The method of selecting articles used as the source of the review is done by random searching using a search engine in the web of related and relevant journals, Google and Google Scholar, using the keywords virtual reality, augmented reality, mixed reality and cultural heritage. The articles listed in the search results were then selected based on the unique content in the proposed development method. The number of articles was limited to 40 to 50 articles where the number is subjectively considered sufficient to represent the topic of discussion.

There are eight challenges identified in the collected articles: (1) time-based 3D reconstruction, (2) object characteristics or typology, (3) 3D reconstruction method, (4) application category, (5) research objective, (6) data management, (7) presentation method and (8) research evaluation. These eight challenges are not a procedure.

A brief explanation of $\mathrm{CH}, \mathrm{VR}, \mathrm{AR}$ and $\mathrm{MR}$ is described before entering into the main discussion. $\mathrm{CH}$ definition from The United Nations Educational, Scientific and Cultural Organization (UNESCO) is [1]:

"cultural heritage is, in its broadest sense, both a product and a process, which provides societies with a wealth of resources that are inherited from the past, created in the present and bestowed for the benefit of future generations. (https://en.unesco.org)"

The keywords of past, present and future in the $\mathrm{CH}$ definition are associated with conservation, and conservation requires educational efforts. The rapid development of information and communication technology is driving the implementation of computer and mobile technology as part of conservation and educational efforts for $\mathrm{CH}$ objects. These technologies can reach all humans, and can transform $\mathrm{CH}$ objects into digital form for human access without being limited by time and space.

During these decades, VR, AR and MR applications have developed rapidly and are widely used for the preservation of $\mathrm{CH}$ objects. In a limited definition: VR is a technology that can support users to interact with a $3 \mathrm{D}$ environment using electronic devices to feel the sensation of being in a virtual environment, and examples of electronic devices used in VR are the HTC Vive, Oculus Rift and PlayStation VR (PSVR), while AR simulates 3D models in a real environment that typically uses a mobile device, and MR is a combination of VR and AR which involves the interaction between humans, computers, virtual environments and real environments. All of these technologies use 3D models to create backgrounds for 
virtual environments, or properties within real and virtual environments.

The structure of the rest of this paper is divided into sections as follows: Section II describes the time-based reconstruction in the $3 \mathrm{D}$-based conservation development; Section III introduces object characteristics of cultural heritage and natural heritage; Section IV discusses the 3D reconstruction method; Section $\mathrm{V}$ describes the applications category; Section VI discusses the research objective; Section VII describes the data management; Section VIII discusses the presentation method; Section IX describes the research evaluation; Section $\mathrm{X}$ describes the analyzes that have been carried out and the development of the proposed model; and Section XI discusses the conclusion and future works.

\section{TIME-BASED 3D RECONSTRUCTION}

Basically, the 3D-based conservation development can be classified into two main time-based 3D reconstruction types, which are the current and past environments. The current environment-based 3D reconstruction refers to restored historical objects that were abandoned or damaged but have undergone restoration in accordance with, or at least close to, their conditions in the past, such as works of [2-7]. Meanwhile, the past environment-based 3D reconstruction is an effort to reconstruct the damaged or extinct historical objects based on their conditions in the past, such as works by [8-10].

The Old-Segeberg town house, a historic building located in German, was reconstructed into a 3D model for a CH-VR application [11]. Preserved artefacts in the city of Rethymno, Greece were reconstructed in 3D models by [2] in order to develop a $3 \mathrm{D}$ game-based learning by combining VR and AR and 360-degree video. These researches have a technical problem as one of the challenges, which is determining the best method in the use of VR or MR technology. This typical problem generally focuses on the technique of $3 \mathrm{D}$ reconstruction and connecting $3 \mathrm{D}$ model into $\mathrm{VR}$, as well as in the works by [6-7]. A project called 3-D Digital Conservation of At-Risk Global Cultural Heritage (3DP-ARCH) to document transnational at-risk heritage objects and places was conducted by [5]. The 3D-ARCH project does not only focus on the documentation of cultural heritage objects, but it includes on the access to big data containing 3D models where big data management is the main problem in this project. An interactive multimedia-based model for the development of a VR application containing a collection of Bulgarian Cultural Heritage Sites was proposed by [3]. The proposed model contains texts, images and videos, 3D models and Audio records. This model is similar to the works by [5] but with a smaller area, which is within one nation. The real area where the cultural heritage objects are scattered, either transnational or within one nation, has the same problem in collecting data. Meanwhile, the number of the reconstructed objects determines the use of big data management. In this case, the model proposed by [3] lacks detail on data management issues, it tends to describe content and navigation of the application without addressing data management problems as [5] did.
In a work called Viking VR, [12] involved the museum curatorial and technical staff and archaeologist to reconstruct an environment of the Vikings era in Britain, as well as [10] who reconstructed the City of Nafplio in $19^{\text {th }}$ century in 3D models by involving archaeologists and historians. Instead of involving archaeologists, [8-9] used a computational-based method in reconstructing damage and extinct objects. A computational-based method using a text-based documentation of classic archeology, sketches and images was proposed by [8] to reconstruct an extinct historical object, the Etruscan Tomb located in Italy, into 3D models. Meanwhile, a direct survey to collect architectural details, architectural analysis based on images, active sensors to control and compare results and deformations was conducted by [9] in order to reconstruct a damage historical object, the Castra Praetoria's walls located in Italy. Unfortunately, both [8] and [9] did not report an archaeologist expert evaluation to judge the suitability of the $3 \mathrm{D}$ models to the past environment. An evaluation of the reconstructed 3D model was conducted by comparing it to the historical pictures and literatures [9]. However, if archaeologists are not involved in reconstructing damage or extinct objects, the reconstructed 3D evaluation by archaeologists is a must.

The current environment-based 3D reconstruction focuses on the problem solving of $3 \mathrm{D}$ reconstruction method selection, application type selection (VR or AR or MR) and data management. Principally, the $3 \mathrm{D}$ reconstruction refers on the current state of the object as it is, so the involvement of archaeologists is optional. But when it involves more than just a visualization of cultural heritage objects. For example, capturing data which needs archaeological analysis and curation such in a work by [5], archaeologists must be part of a team. Meanwhile, the past environment-based 3D reconstruction also focuses on the problem solving in the current environment-based $3 \mathrm{D}$ reconstruction, but it needs the involvement of archaeologists in reconstructing the damaged or extinct historical objects based on the past environment or in evaluating the suitability of the reconstructed $3 \mathrm{D}$ model to the scientific description of the object as it was in the past time.

\section{OBJECT CHARACTERISTICS (TYPOLOGY)}

There is debate regarding the definitions of $\mathrm{CH}$ and natural heritage $(\mathrm{NH})$. Some argue that $\mathrm{CH}$ is a man-made product, while NH is a gift from nature. Meanwhile, UNESCO defines $\mathrm{CH}$ by using the phrase 'works of man or the combined works of nature and man' but $\mathrm{NH}$ is defined without mentioning a single word of man [1]. So, we agree with the definition of $\mathrm{CH}$ as a man-made product. Furthermore, if there are two terms $\mathrm{CH}$ and $\mathrm{NH}$, there should be a distinction between them, and man-made or not is a fundamental differentiator for defining the two terms. Based on our agreed definition of $\mathrm{CH}$, an $\mathrm{AR}$ work of [13] containing the Pietraroja paleontological site visualization, which includes reconstructions of extinct living things, is not $\mathrm{CH}$ as stated in the article title, and $\mathrm{NH}$ is the appropriate term to use. Regardless of the inaccuracy in the use of the term, we continue to study this work by considering the content containing the AR development methods. 
Next is to define objects that is used for 3D-based $\mathrm{CH}$ conservation. Old buildings do not always fit $\mathrm{CH}$ objects. An object must comply with traditional, chronological and geographical concepts, where the object is not only historical and artistic but must have cultural values or memory capacities within the object [14]. Thus, a list of $\mathrm{CH}$ objects released by local authorities or UNESCO can be used to confirm this.

The object characteristics include the size, number, location and structure. A sophisticated project, 3-D Digital Preservation of At-Risk Global Cultural Heritage (3DP$\mathrm{ARCH}$ ), conducted by [5] contains a large size and number of objects with varying structural complexity, as well as locations spread across nine countries. In contrast to 3DP$\mathrm{ARCH},[10]$ tried to reconstructed the historical city of Nafplio in Greece, as well as [15] who tried to reconstruct the various sizes and numbers of objects in an area called Little Manila in California, US, back in the 1940s. Meanwhile, [9] reconstructed objects with simpler complexity but have a broad size, which are ancient walls located in an area of nearly 17 hectares, as well as [16] who reconstructed a single complex object called the Roman Theater at Byblos located in Lebanese. The four conservation buildings where the Princeton University Campus is located were reconstructed by [17], and [18] reconstructed the Museum of King John III's Palace at Wilanów in Warsaw, Poland consisting of five rooms. The Dudsbury Hillfort visualization by [19] is a reconstruction of a typical large 3D landscape. Artifacts which are typical of small objects, are part of the $3 \mathrm{D}$ reconstruction. The Etruscan Tomb in Italy, including artifacts of funerary equipment, was reconstructed by [8], while [20] reconstructed relics collection of the Majapahit kingdom, Indonesia, and [21] reconstructed Haw Par Villa in Singapore, including two sumo statues.

A detailed analysis of the object characteristics determines the success of the 3D-based $\mathrm{CH}$ conservation development. There are cases of 3D reconstructions of objects that are large or extensive but have less structural complexity (ornamentation) than a single building, or even small artifacts. The challenge is to appropriately measure the object typology. This is essential for the initialization stage of 3D-based $\mathrm{CH}$ conservation development, and is related to the resources owned, including funding, so that there is no excessive target as in the conceptual model proposed by [3] which targets the $3 \mathrm{D}$ reconstruction of all historical sites in Bulgaria without being supported by a clear design of the model implementation and research timeline, considering that one research project must have a clear duration in its implementation.

\section{3D RECONSTRUCTION METHOD}

Some of the works relied on documentation of cultural heritage objects and software engineers including the use of artificial intelligence methods in $3 \mathrm{D}$ reconstruction. Considering the $3 \mathrm{D}$ model is a basic component of delivering information, the reconstruction must be carried out carefully so as not to mislead. Methodology in 3D reconstruction is divided into survey-based such as laser scanning and photogrammetry, and reconstruction-based which involves an interdisciplinary team to work based on documentation of cultural heritage objects [22]. Reconstruction-based techniques uses traditional 3D modeling technique, where the modeling process is conducted based on notes, literatures, images, building blueprint, videos and other documentations. Meanwhile, the survey-based technique uses a collection of photos (sequence) for automatic 3D modeling based on artificial intelligence approach.

A 3D reconstruction of ancient walls located in an area of nearly 17 hectares were reconstructed using a number of total stations to do topographic survey where the results were then used to control the photogrammetric model, and also a direct observation was conducted to get some of the architectural details used for the 3D model texture [9]. Laser scanning and photogrammetry were also used by [18] for a 3D reconstruction of a historic building. Images or photos used for input in photogrammetry must be properly prepared. The different cameras and resolutions used to capture the data from a single object provide more complexity for automatic $3 \mathrm{D}$ reconstruction. The number of vertices (cloud subsampling) were reduced using random method [18].

A 3D reconstruction of the Etruscan hypogeum tomb complete with the funerary equipment was conducted by [8] a combination of survey-based and reconstruction-based techniques, in which small artefacts from funerary equipment were reconstructed using a laser scanner and the tomb was reconstructed using a traditional 3D modeling technique. They also conducted an addition $3 \mathrm{D}$ reconstruction for damaged artefacts. The damage artefacts, which firstly were reconstructed using a laser scanner, were continued to be restored using a traditional 3D modeling technique. The division of reconstruction tasks by reconstruction-based has a dominant portion of the survey-based was performed in a 3D reconstruction was performed by [13] and [23]. In a 3D reconstruction of an ancient Roman house by [23], photogrammetry was used only for walls, while the building was reconstructed using traditional 3D modelling. Meanwhile, [13] prefer to use traditional 3D modeling to reconstruct fossil forms based on documentation of living species that have become extinct at the paleontological site of Pietraroja, Italy.

One of the challenges in $3 \mathrm{D}$ reconstruction is that $3 \mathrm{D}$ modeling requires high computer specification. Photogrammetry is currently the most 3D reconstruction technique used in many researches; it provides low cost of both software and hardware [24]. However, survey-based techniques used for complex structures or large objects still require much higher computer specifications. Moreover, the precision of 3D models reconstructed using photogrammetry technique depends on the object's real environment and object size, where only isolated building and small artefacts are suitable for this technique [8, 25]. The use of survey-based reconstruction for automated $3 \mathrm{D}$ reconstruction as well as traditional 3D modeling techniques for reconstruction requires more time and human resources. Appropriate preparation based on time-based reconstruction analysis and environmental analysis of objects including budget should be made to select the $3 \mathrm{D}$ reconstruction method, whether surveybased or reconstruction-based or combine the two methods. 


\section{APPLICATION CATEGORY}

The selection of the category of application is in accordance with the type of time-based reconstruction that underlies application development which in general can be categorized in documentation and restoration. The use of timebased representation is to limit the definition of documentation and restoration, and to avoid bias in the terminology of restoration which also can be defined as part of documentation work.

In the context of time-based reconstruction, the documentation category relates to current environment-based reconstruction, while the restoration category relates to past environment-based reconstruction. Documentation means visualization in which physical $\mathrm{CH}$ objects are transformed into virtual forms so that users can virtually see $\mathrm{CH}$ objects. When an element of restoration is added to the visualization, the category changes from documentation to restoration.

The category of documentation can be found in the example of work in The Visualization of Dudsbury Hillfort by [19], The Visualization of the Selimiye Mosque of Edirne by [4], 3DP-ARCH by [5], Tomb of Sultan by [26] and Capturing Aboriginal Heritage by [27]. Meanwhile, the category of restoration can be found in the example of work in Aurelian Wall at Castra Praetoria by [9], The Ancient City of Sarmizegetusa by [28], The Church of Santa Maria Paganica in L'Aquila by [29], Nafplio in the $19^{\text {th }}$ Century by [10] and The Restoration Project of Alaca Imaret Câmi by [30]. In most of cases, combination of survey-based and reconstructionbased methods is performed for 3D reconstruction for either the documentation or reconstruction category.

\section{RESEARCH OBJECTIVE}

In the field of computer science, specific objective is related to the application development methodology based on its categories, either documentation or restoration. In other words, specific objective is to find appropriate methods to document or restore a $\mathrm{CH}$ object in the form of a 3D model and present it using VR or AR or MR. Meanwhile, general objective is related to the needs of users, such as for education, economic and tourism.

In fact, some researchers tend to focus on immersive outcomes or the works of technology without clearly evaluating the achievement based on the general objective. Especially for educational objectives where many studies claim that its application was developed for education. Delivering education is not just showing things. There must be a set of parameters or at least or general description to measure the achievement of education delivery which is not found on the reports in the development of $\mathrm{AR}$ for the Monuments of Crete by [2], AR for the Paleontological Site of Pietraroja by [13], and AR-based Art Gallery for education by [31]. In contrast with [32] who performed a comparison test by control and treatment groups involving a number of students in evaluating their work called ScollAR, a digital learning platform containing VR section and AR section to deliver education. Meanwhile, [33] used Software Usability Measurement Inventory (SUMI) model, a survey instrument to measure user perceptions of software usability, to evaluate their work containing VR for The Island of San Andres.

Referring to the definition of museum, virtual museum is a type of application for education. The definition of museum includes the educational element as [34] states that:

"the missions of museum do not only consist of conserving and exhibiting treasures and objects that provide us with information but include the provision of educational tasks" ( $p$. 1257).

The International Council of Museums (ICOM) also emphasizes that the educational element is part of the definition of museum. The ICOM states that [35]:

"a museum is a non-profit, permanent institution in the service of society and its development, open to the public, which acquires, conserves, researches, communicates and exhibits the tangible and intangible heritage of humanity and its environment for the purposes of education, study and enjoyment".

The example of virtual museum can be found in the development of Alt-Segeberger Bürgerhaus by [11], Viking VR by [12], Virtual Artifact by [20] and The Maritime Museum of Kotor by [36]. Regardless of the use of the term virtual plaza rather than museum, [3] proposed an excessive target in documenting all $\mathrm{CH}$ sites in Bulgaria without a clear methodology for data management. The same thing happened to several other researchers who used the term virtual museum without paying attention to the fulfillment of the rules and characteristics of the museum or without explaining the implementation of how the museum works in their application which basically they are trapped in visualization or developing application in the domain of documentation category, or might be in the education category but not delivered in museum form. VR development for museums often does not consider museum's concept and policies [37] and neglects visitor experience related to the real experience of visiting museums, and museum systems and organizations [38].

Another general objective in developing VR or AR or MR for $\mathrm{CH}$ objects is to support the economy as [39] proposed in extending VR and AR applications with 3D printing feature for an economy value, while examples for tourism can be found in the work of the Deoksugung palace in South Korea and the An Post Museum in Republic of Ireland virtual tours by [40], the Princeton University Campus virtual tours by [17] and The Jeju-mok Government Office and the Gwandeokjeong Pavilion virtual tours by [41].

\section{DATA MANAGEMENT}

Object characteristics, 3D reconstruction methods, application categories, and research objectives influence the complexity of data management. Data management includes management of data source, collected data, 3D reconstruction data, 3D model data, application log data and others including metadata management. All data categories must be related to each other to support application maintenance, application performance enhancements, and application extends or updates. There is a lot of discussion material for data management that is not sufficient to cover in this article. 
Several examples of case studies in data management are used to open up insights.

A clear example can be found in the development of a virtual museum. Learning in museums should support a constructivist approach that allows visitors to gain knowledge spontaneously through their personal experiences, and virtual museums can support such learning [42]. Thus, data management mechanisms in real museums must be implemented in virtual museums. In this case, data management is not only applied to historical objects, stakeholder engagement data also needs to be managed. In order to substitute the role of historians who accompany and answer visitor questions, [36] proposed a method of information retrieval in managing object information data, by allowing users to enter keywords in the application which are then sent to the database via the internet to obtain information on the object. Another example in historic building is [43] who focused on managing metadata containing historic building information to support context-aware risk management for people who follow the update of information on the $\mathrm{CH}$ object.

Data management in VR, AR or MR application development is rarely found in related articles, and the topic is still wide open for research. Many challenges are faced in it. The metaphorical principle that implements the design of a real object or system into an application needs to be considered.

\section{PRESENTATION METHOD}

The presentation method refers to the selection of VR or AR or MR technology for 3D-based conservation application, including the way to present the application to the users. The VR museum environment must be designed as immersive as possible in order to attract users to enjoy educational and entertainment experiences including influencing users to physically visit the museum [44]. Indeed, even all categories of applications, whether VR, AR or MR and their extensions, such as games or virtual museums and others should consider the immersive output in their presentation. On the other hand, 3D data management requires high costs, at least for the provision of computers with high specifications. This includes the users who must use a device with high specifications to be able to run 3D-based applications.

One of the challenges in presenting 3D-based applications is the ease of access through devices owned by the user directly, which can be a smart phone, tablet or computer. On the other hand, user-owned devices have very varied specifications. Therefore, the determination of visual quality must consider the computation load that must be carried by the device to run the application.

In general, the visual quality of a $3 \mathrm{D}$ model is highly dependent on the number of $3 \mathrm{D}$ points that are used to construct or deform objects, and on rendering techniques that involve textures and lighting. The number of $3 \mathrm{D}$ points affects the render speed. Therefore, low-poly 3D models are preferred for applications that run on mobile devices, especially smart phones. Real-time rendering for high quality 3D environment on mobile devices is a challenge in developing 3D-based applications [45]. At this stage, the role of the $3 \mathrm{D}$ engineer is decisive. Researchers can coordinate with 3D engineers to make observations on several applications to run on several device specifications as a comparison. Observation results can be used to determine visual quality based on target device specifications. Immersive reality can be obtained using the following devices: head mounted display with video and optical see-through used for AR or MR and blocked headsets used for VR, spatial augmented reality, hand-held-devices, desktop screen and projection, and cave automatic virtual environment (CAVE) [46]. The 3D-ARCH project conducted by [5] does not only focus on the development of building a $3 \mathrm{D}$ environment and augmented reality interaction, but it includes on how to organize big cultural heritage data to be virtually learned using head mounted device, CAVE, mobile augmented reality devices platform, big screen television with high-speed access to the 3D processing, high quality render and high-capacity data storage, all of which are very expensive, including the use of a supercomputer. Of course, not all projects are sophisticate with high budgets.

With all the limitations in the hardware, AR provides a breakthrough in easy access to 3D-based applications by allowing users to interact with applications using their own mobile devices. Moreover, during and after the Covid-19 pandemic era, hygiene issues will affect user behavior regarding the use of VR support devices, such as head mounted devices. In a new normal era, it is not recommended to use one device for multiple users without implementing health protocols. This condition becomes a dilemma, adding devices means increasing budgets, while using a limited number of devices means increasing the frequency of cleaning, and this can have an adverse impact on the smooth functioning of the devices.

At present, VR and AR technologies for 3D-based $\mathrm{CH}$ conservation have been found in various studies, while the application of MR technology is still limited, because MR technology has enormous challenges [46]. Devices to support MR, such as Google ARCore, Apple ARKit and Microsoft MixedReality-Toolkit only conceived for indoor usage, and these devices are not support for outdoor experience [47]. Changes in environment and movement of objects are still a problem in MR, including its application to mobile applications [48]. An example of MR for $\mathrm{CH}$ is showed by [25] who displayed the 3D environment that the user sees through the HoloLens onto the monitor screen.

In addition to virtual museums, game applications are also applied in 3D-based $\mathrm{CH}$ conservation such as the historical city of Nafplio by [10], Viking VR by [12] and The Little Manila in the late 1940s in California by [15]. One of the challenges in using games for $\mathrm{CH}$ conservation is the screenplay that doesn't change history. Another challenge is the development of intelligent virtual agents that are able to socially interact with users [49]. The existence of intelligent virtual agents in the 3D-based $\mathrm{CH}$ conservation are interesting. It is like watching a Jurassic Park movie not through the screen, but being in it. It gives more challenge and worth studying, in which cinematography may also be used to characterize the intelligent virtual agents. 


\section{RESEARCH EVALUATION}

Four parameters, which are the presence, enjoyment, attitude change, and visit intention, were used by [41] to evaluate user acceptance for a VR application in which TV video clips were inserted. Meanwhile, [33] used SUMI method which consists of efficiency, affect (likeability), helpfulness, control, learnability and global measurement for evaluation based on user acceptance. A different evaluation method was proposed by [50] who added 360-degree video storytelling to a VR application, and used electroencephalography (EEG)) to evaluate user acceptance based on brain signals data related to factors of the presence, engagement, and immersion that are obtained after playing the application. In addition to measuring the ease of operation of the application, [19] conducted a survey to evaluate the similarity of the 3D model to the original object, and the level of realistic.

Most of researchers use survey techniques to get feedback about the application, such as using the SUMI method. In measuring the level of immersion or the similarity between 3D models with the original objects or the application functions design and others, most researchers also use feedback from users without an appropriate respondent screening method.

There is a gap in these measurement cases. Users who never or rarely use VR, AR or MR applications have a tendency to give good feedback. On the other hand, users who have a lot of experience in using the application, or experts in VR, AR or MR, can provide more valuable feedback. Archaeologists, historians and other relevant experts have a capacity to evaluate a similarity measurement. Applications are developed for use by users; therefore, users should give their opinion which can be used to measure the achievement of output, but the method of collecting opinions about the application must be designed more clearly and rigidly. Other challenges in designing evaluations are: measuring real work systems by applying them to applications as in the case of virtual museums, measuring data management on artifact collections, or computations as the specific objectives.

\section{DISCUSSION}

Eight challenges, which are time-based 3D reconstruction, object characteristics or typology, 3D reconstruction method, application category, research objective, data management, presentation method and research evaluation, including the problem-solving method identified and described above are interesting and very helpful in developing the model of 3Dbased $\mathrm{CH}$ conservation (Fig. 1). Before designing the research implementation, the trivial thing that can make a big impact is to be sure the target object is part of the cultural heritage category.

The center of the model is the research objective which consists of specific objectives related to the designation of the application being developed, and general objectives that can be for education, economic and tourism. The research objective has typical problem-solving in data management, 3D reconstruction and presentation methods. In the diagram, the three problem-solutions are denoted by dashed lines and gray boxes. Even so, it does not rule out problem-solving in developing a model or method for typology analysis and research evaluation.

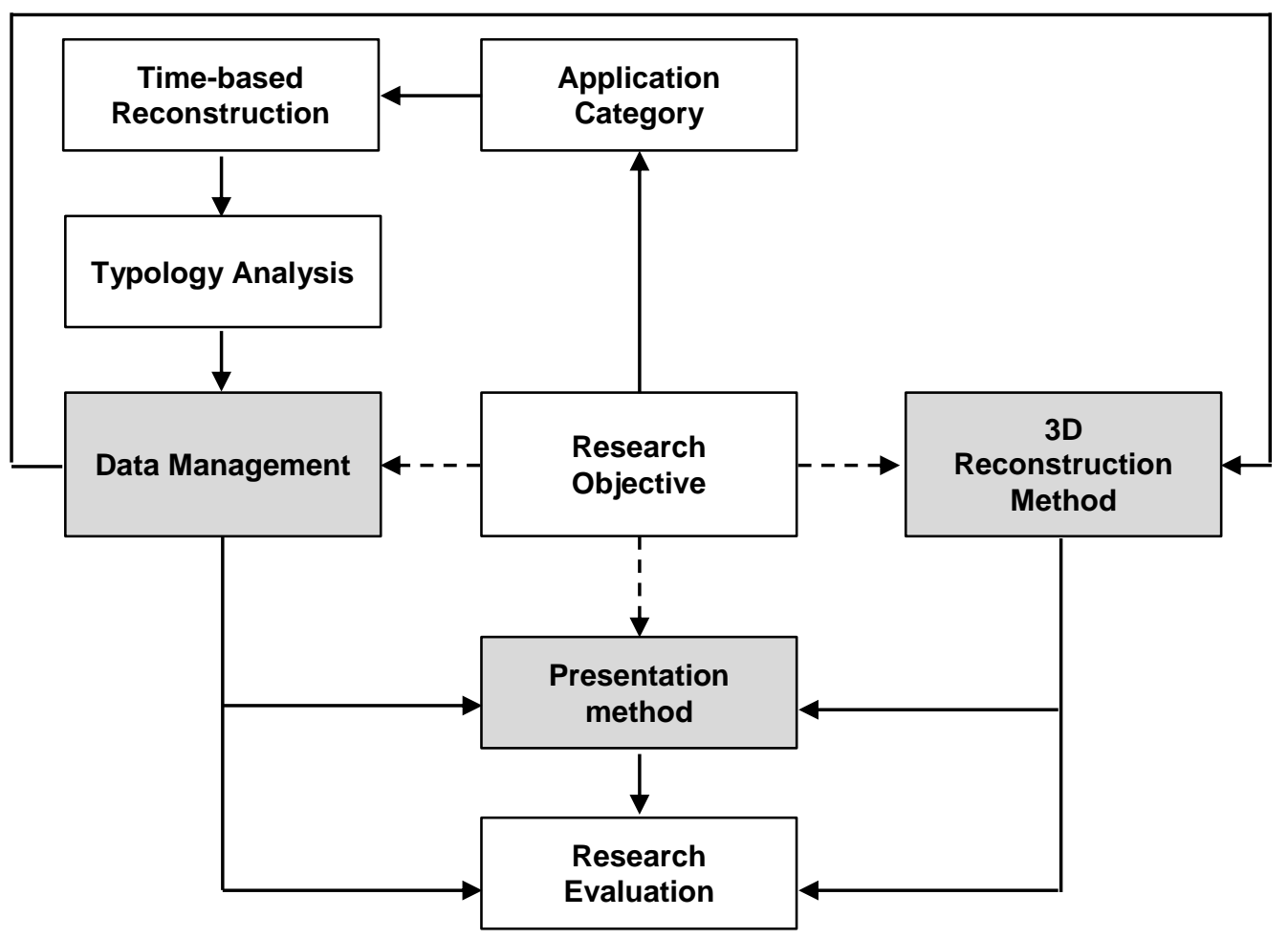

Fig. 1. 3D-based CH Conservation Development Model 
Back to research objective as the center of the model. Once the objective is determined with a confirmed $\mathrm{CH}$ object, the application category, either documentation or restoration, can be identified. The restoration category relates to an effort to reconstruct the damaged or extinct historical objects based on their conditions in the past, while the documentation category relates to a $3 \mathrm{D}$ reconstruction based on the current state of the real environment. The application category defines the time-based reconstruction. The documentation category is derived to the current environment-based reconstruction, while the restoration category is derived to the past environment-based reconstruction. The involvement of archaeologists and historians can be an option in environmentbased reconstruction today, but is obligation in environmentbased reconstruction of the past. Furthermore, typology analysis is carried out to collect data based on object characteristics. Analysis can be conducted through direct observation or documentation-based. The results of the analysis are sent to the data management.

Data management controls data flow from research design, and before, during and after 3D reconstruction, including presentation methods, research evaluation, and during application use. The challenge in data management is finding the best method of organizing the various data categories to support easy data management and information access, both for developers, clients (such as museum managers) or application users. Data management has challenges that are still wide open for research in this topic, especially in developing applications that have characteristics such as virtual museums where human-computer interactions data must be processed while the application is used. In the data management, the typology data are used to determine data collection technique in order to select the $3 \mathrm{D}$ reconstruction method.

The 3D reconstruction method is divided into survey based and reconstruction based. Survey-based using photogrammetry, laser scanning and other supporting tools, such as a total station. Meanwhile, the one based on reconstruction is traditional $3 \mathrm{D}$ modeling. The challenge in this task is finding the best method to make a 3D model as closely as possible to the original object as in the work of Cai et al. (2016) and Canciani et al. (2016). The combination of survey-based and reconstruction-based methods for 3D reconstruction is the most widely used, in fact the combination of these two methods has become an integral part of the past environment-based reconstruction. Determination of the proportion of the combination can be done by considering the characteristics of the object. Furthermore, the reconstruction of the object into the 3D model begins, including the application of textures, also including other tasks that have been defined in the data management.

The results in the $3 \mathrm{D}$ reconstruction and data management are applied in the presentation methods in which VR, AR or MR applications are developed. Challenges in presentation methods include data management implementation, VR or AR or MR technology selection, visual quality (immersive application) control, human-computer interaction method selection and the graphical user interface design.
After the application is finished, evaluation is carried out to measure the achievement of defined general objectives and specific objectives. Research is evaluated by measuring the achievement of the proposed problem-solving which can be based on the efficiency and or effectiveness of the computational load in the $3 \mathrm{D}$ reconstruction process or in presentation method or in data management, or stakeholder perceptions.

The development of 3D-based $\mathrm{CH}$ conservation involves individuals from various backgrounds, such as archaeologist, historian, curatorial, 3D engineers, sound engineer, programmer and others, including stakeholders. Expert test by involving archaeologists, historians, curators and graphic designer can be carried out to measure various elements related to the object being modeled into 3D. User acceptance test by involving related experts and users can be performed to measure the acceptance of perceptions from stakeholders. SUMI evaluation model like the one used by Musa et al. (2018) can be applied in user acceptance test. Other testing methods may also be performed, such as data management testing or testing based on computational processes.

\section{CONCLUSION AND Future WORK}

The use of VR, AR and MR in 3D-based $\mathrm{CH}$ conservation is growing rapidly. On the other hand, there are still researches with poor planning as found in several articles in these case studies. This article aims to develop a 3D-based $\mathrm{CH}$ conservation model that implements VR, AR and $\mathrm{MR}$ technology using the case study method. The model provides a clear description as a practical guide for researchers just beginning research on this topic.

For future work, the model will be implemented and tested in 3D-based $\mathrm{CH}$ conservation for a historical building object called Lawang Sewu located in the city of Semarang, Indonesia.

\section{ACKNOWLEDGMENT}

Thank to Ministry of Research, Technology, and Higher Education of The Republic Indonesia for financial support through the $1^{\text {st }}$ year Hibah Penelitian Terapan Tahun 2021.

\section{REFERENCES}

[1] https://en.unesco.org/creativity/sites/creativity/files/cdis/heritage_dimen sion.pdf/ (accessed on May 5, 2021).

[2] L. Argyriou, D. Economou, and V. Bouki, "360-degree Interactive Video Application for Cultural Heritage Education", in: $3^{\text {rd }}$ Annual International Conference of the Immersive Learning Research Network. 26-29 June 2017, Coimbra, pp. 297-304. DOI: 10.3217/978-3-85125530-0-44.

[3] A. Bachvarov, D. Chotrov, Y. Yordanov, and Z. Uzunova, "Conceptual Model of the VR Module for Virtual Plaza for Interactive Presentation of Bulgarian Cultural Heritage", in: AIP Conference Proceedings 2172, 7-13 June 2019. Sozopol, Bulgaria, pp. 1-5. DOI: 10.1063/1.5133585.

[4] T.P. Kersten, B. Büyüksalih, F. Tschirschwitz, T Kan, S. Deggim, T. Kaya, and A.P. Baskaraca, "The Selimiye Mosque of Edirne, Turkey An Immersive and Interactive Virtual Reality Experience using HTC Vive", in The International Archives of the Photogrammetry, Remote Sensing and Spatial Information Sciences, Volume XLII-5/W1, 22-24 May 2017, Florence, Italy, pp. 361-367. DOI: 10.5194/isprs-archivesXLII-5-W1-403-2017.

[5] N. Lercari, J. Schulze, W. Wendrich, B. Porter, M. Burton, and T.E. Levy, "3-D Digital Conservation of at-risk Global Cultural Heritage", 
Catalano, C.E., De Luca, L. (Eds), Eurographics Workshop on Graphics and Cultural Heritage, 2016, pp. 193-197. DOI: 10.2312/gch.20161395.

[6] B.J. Fernandez-Palacios, D, Morabito, and F. Remondino, "Access to Complex Reality-Based 3D Models using Virtual Reality Solutions", Journal of Cultural Heritage, 23(2017), pp. 40-48. DOI: 10.1016/j.culher.2016.09.003.

[7] E.Y. Putra, A.K. Wahyudi, and C. Dumingan, "A Proposed Combination of Photogrammetry, Augmented Reality and Virtual Reality Headset for Heritage Visualization" in 2016 International Conference on Informatics and Computing (ICIC), 28-29 October 2016, Mataram, Indonesia, pp. 43-48.

[8] S. Batino, M. Callieri, D. Duranti, M. Dellepiane, P. Pingi, E. Siotto, and R. Scopigno, "Virtual Reconstruction of an Etruscan Tomb", in $17^{\text {th }}$ International Conference on Cultural Heritage and New Technologies, 5-7 November 2018, Vienna, Austria, 13 pages.

[9] M. Canciani, E. Conigliaro, M. Del Grasso, P. Papalini, and M. Saccone, "3D Survey and Augmented Reality for Cultural Heritage. The Case Study of Aurelian Wall at Castra Praetoria in Rome", in The International Archives of the Photogrammetry, Remote Sensing and Spatial Information Sciences, Volume XLI-B5, 12-19 July 2016, Prague, Czech Republic, pp. 931-937. DOI:10.5194/isprsarchives-XLI-B5-9312016.

[10] A. Kargas, G. Loumos, and D. Varoutas, "Using Different Ways of 3D Reconstruction of Historical Cities for Gaming Purposes - The Case Study of Nafplio", Heritage, 2(3), 2019, pp. 1799-1811. DOI: 10.3390/heritage2030110.

[11] T.P. Kersten, F. Tschirschwitz, "Development of a Virtual Museum Including a 4D Presentation of Building History in Virtual Reality", in The International Archives of the Photogrammetry, Remote Sensing and Spatial Information Sciences, Volume XLII-2/W3, 1-3 March 2017, Nafplio, Greece, pp. 403-409. DOI: 10.5194/isprs-archives-XLII-2-W3361-2017.

[12] G. Schofield, G. Beale, N. Beale, M. Fell, D. Hadley, J. Hook, D. Murphy, J. Richards, and L. Thresh, "Viking VR: Designing a Virtual Reality Experience for a Museum", in Proceedings of the 2018 Designing Interactive Systems Conference, June 2018, Hongkon, China, pp. 805-815. DOI: 10.1145/3196709.3196714.

[13] R. Fistola, A. Rastelli, C. Pham, and F.O. Amore, "Augmented Reality for Cultural Heritage: A New Dimension for the Perceptual Knowledge", Materials Science and Engineering, 949, 012053, 2020, pp. 1-9. DOI: 10.1088/1757-899X/949/1/012053.

[14] M. Vecco, A definition of cultural heritage: From the tangible to the intangible. Journal of Cultural Heritage, 11 (2), 2010, pp. 321-324. DOI: 10.1016/j.culher.2010.01.006.

[15] S. Vu, D. Cliburn, J. Helgren, J. Salyers, K. Canniff, A. Johnson, M. Milliken, T. Reardon, K. Sabbatino, and A. Stephan, "Recreating Little Manila through a Virtual Reality Serious Game", in $3^{\text {rd }}$ Digital Heritage International Congress held jointly with $24^{\text {th }}$ International Conference on Virtual Systems \& Multimedia, San Francisco, CA, USA, 2018, pp. 1-4, DOI: 10.1109/DigitalHeritage.2018.8810082.

[16] G. Younes, R. Kahil, M. Jallad, D. Asmara, I. Elhajj, G. Turkiyyah, and H. Al-Harithy, "Virtual and Augmented Reality for Rich Interaction with Cultural Heritage Sites: A Case Study from the Roman Theater at Byblos". Digital Applications in Archaeology and Cultural Heritage, 5, 2017, pp. 1-9. DOI: 10.1016/j.daach.2017.03.002.

[17] R.K. Napolitano, G. Scherer, and B. Glisic, "Virtual Tours and Informational Modeling for Conservation of Cultural Heritage Sites". Journal of Cultural Heritage, 29, 2017, pp. 123-129. DOI: 10.1016/j.culher.2017.08.007.

[18] K. Choromański, J. Łobodecki, K. Puchała, and W. Ostrowski, "Development of Virtual Reality Application for Cultural Heritage Visualization from Multi-Source 3D Data", in The International Archives of the Photogrammetry, Remote Sensing and Spatial Information Sciences, Volume XLII-2/W9, 6-8 February 2019, Bergamo, Italy, pp. 261-267. DOI: 10.5194/isprs-archives-XLII-2-W9261-2019.

[19] D. John, D. Hurst, P. Cheetham, and H. Manley, "Visualising Dudsbury Hillfort: Using Immersive Virtual Reality to Engage the Public with Cultural Heritage. Robert, S., Michael, W. (Eds), Eurographics
Workshop on Graphics and Cultural Heritage, 2018, pp. 193-197. DOI: 10.2312/gch.20181360.

[20] A.G. Sooai, A. Nugroho, M.N. Al Azam, S. Sumpeno, and M.H. Purnomo, "Virtual Artifact: Enhancing Museum Exhibit using 3D Virtual Reality", in 2017 TRON Symposium (TRONSHOW), Tokyo, 13-14 December 2017, Tokyo, Japan, pp. 1-5. DOI: 10.23919/TRONSHOW.2017.8275078.

[21] B. Tan, Y. Cai, Y. Zhang, X. Wu, Y. Chen, and B. Yang, "Virtual Reality Continuum for Heritage at Haw Par Villa in Singapore", in VRCAI '16: Proceedings of the Symposium on VR Culture and Heritage, 3 December 2016, Zhuhai, China, pp. 71-74. DOI: $10.1145 / 3014027.3014030$.

[22] R.P. Barratt, "Defining a Methodology for 3D Approximations in Archaeology: The Issue with Alternative Models", in $23^{\text {rd }}$ International Conference on Cultural Heritage and New Technologies, 12-15 November 2018, Vienna, Austria, 12 pages.

[23] R.G. Boboc, M. Duguleană, G-D. Voinea, C-C. Postelnicu, D-M. Popovici, and M. Carrozzino, "Mobile Augmented Reality for Cultural Heritage: Following the Footsteps of Ovid among Different Locations in Europe". Sustainability 11(4), 1167. 2019. DOI: 10.3390/su11041167.

[24] J. Pakkanen, A. Brysbaert, D. Turner, and Y. Boswinkel, "Efficient Three-Dimensional Field Documentation Methods for Labour Cost Studies: Case Studies from Archaeological and Heritage Contexts", Digital Applications in Archaeology and Cultural Heritage, 17(2020) e00141, 2020, pp. 1-12. DOI: 10.1016/j.daach.2020.e00141.

[25] H. Rahaman, E. Champion, and M. Bekele, "From Photo to 3D to Mixed Reality: A Complete Workflow for Cultural Heritage Visualisation and Experience", Digital Applications in Archaeology and Cultural Heritage, 13(2019) e00102, 2019, pp. 1-12. DOI: 10.1016/j.daach.2019.e00102.

[26] Z.S. See, D. Santano, M. Sansom, C.H. Fong, and H. Thwaites, "Tomb of a Sultan: A VR Digital Heritage Approach", in $3^{\text {rd }}$ Digital Heritage International Congress held jointly with 24th International Conference on Virtual Systems \& Multimedia, San Francisco, CA, USA, 2018, pp. 1-4, DOI: 10.1109/DigitalHeritage.2018.8810083.

[27] T. Trescak, A. Bogdanovych, M. Williams, and T. Sloan, "Capturing Aboriginal Heritage in Virtual Reality", in Proceedings of VRST '17, 810 November 2017, Gothenburg, Sweden. DOI: $10.1145 / 3139131.3141213$.

[28] E. Demetrescu, E. d'Annibale, D. Ferdani, and B. Fanini, "Digital Replica of Cultural Landscapes: An Experimental Reality-based Workflow to Create Realistic, Interactive Open World Experiences", Journal of Cultural Heritage, 41, 2020, pp. 125-141. DOI: 10.1016/j.culher.2019.07.018.

[29] G. De Gasperis, A. Cordisco, and F. Cucchiara, "Immersive Virtual Reality as a Resource for Unaccessible Heritage Sites", Materials Science and Engineering, 364, 012035. 2018, DOI: 10.1088/1757899X/364/1/012035.

[30] K. Oudatzi, "Virtual Reality in Restoration of Historic Buildings: 3D Model Projection of the Restoration Project of Alaca Imaret Câmi with Intuitive And Interactive Application Through Hyper Realism Technology", in $16^{\text {th }}$ International Conference on Virtual Systems and Multimedia, 20-23 October 2010, Seoul, Korea, pp. 361-364, DOI: 10.1109/VSMM.2010.5665931.

[31] C. Perra, E. Grigoriou, A. Liotta, W. Song, C. Usai, and D. Giusto, "Augmented Reality for Cultural Heritage Education", i In: IEEE $9^{\text {th }}$ International Conference on Consumer Electronics, 8-11 September, 2019, Berlin, Germany, pp. 333-336. DOI: 10.1109/ICCEBerlin47944.2019.8966211.

[32] M. Puggioni, E. Frontoni, M. Paolanti, and R. Pierdicca, "ScoolAR: An Educational Platform to Improve Students' Learning through Virtual Reality", in IEEE Access, 9, 2021, pp. 21059-21070. DOI: 10.1109/ACCESS.2021.3051275.

[33] R. Zamora-Musa, J. Vélez, and H. Paez-Logreira, "Evaluating Learnability in a 3D Heritage Tour", Presence: Virtual and Augmented Reality, 26(4), 2017, pp. 366-377. DOI: 10.1162/PRES_a_00305.

[34] B. Gunay, "Museum Concept from Past to Present and Importance of Museum as Centers of Art Education", Procedia-Social and Behavioral Sciences, 55, 2012, pp. 1250-1258. 
[35] https://icom.museum/en/resources/standards-guidelines/museumdefinition/ (accessed on June 4, 2021).

[36] A. Sochenkova, N. Podzharaya, P. Trofimov, G. Novikova, "Design and Implementation of Information Retrieval Mechanism for the Virtual Museum Creation", in $7^{\text {th }}$ Mediterranean Conference on Embedded Computing, 10-14 June 2018, Budva, Montenegro, pp. 1-4. DOI: 10.1109/MECO.2018.8406084.

[37] N.A. Haddad, "Heritage Multimedia and Children Edutainment: Assessment and Recommendations", Advances in Multimedia, 2014, 13 pages, DOI: 10.1155/2014/579182.

[38] M. Shehade, and T. Stylianou-Lambert, "Virtual Reality in Museums: Exploring the Experiences of Museum Professionals". Applied Science, 10, 4031. 2020. DOI:10.3390/app10114031.

[39] T.H. Jung, and M.C.T. Dieck, "Augmented Reality, Virtual Reality and 3D Printing for the Co-Creation of Value for the Visitor Experience at Cultural Heritage Places", Journal of Place Management and Development, 10(2), 2017, pp.140-151, DOI: 10.1108/ JPMD-07-20160045.

[40] T.H. Jung, H. Lee, N. Chung, and M.C.T. Dieck, "Cross-cultural Differences in Adopting Mobile Augmented Reality at Cultural Heritage Tourism Sites", International Journal of Contemporary Hospitality Management, 30(3), 2017, pp. 1621-1645. DOI: 10.1108/IJCHM-022017-0084.

[41] H. Park, J. Kim, S. Bang, and W. Woo, The Effect of Applying FilmInduced Tourism to Virtual Reality Tours of Cultural Heritage Sites", in $3^{\text {rd }}$ Digital Heritage International Congress held jointly with $24^{\text {th }}$ International Conference on Virtual Systems \& Multimedia, San Francisco, CA, USA, 2018, pp. 1-4. DOI: 10.1109/DigitalHeritage.2018.8810089.

[42] E. Ch'ng, Y. Li, S. Cai, and F-T. Leow, "The Effects of VR Environments on the Acceptance, Experience, and Expectations of Cultural Heritage Learning", Journal on Computing and Cultural
Heritage, 13, 1, Article 7 (February 2020), 21 pages. DOI: $10.1145 / 3352933$.

[43] J. Lee, J. Kim, J. Ahn, and W. Woo, "Context-aware Risk Management for Architectural Heritage using Historic Building Information Modeling and Virtual Reality" Journal of Cultural Heritage, 38, 2019, pp. 242-252. DOI: $10.1016 /$ j.culher.2018.12.010.

[44] H. Lee, T.H. Jung, M.C.T. Dieck, annd N. Chung, "Experiencing Immersive Virtual Reality in Museums", Information and Management, 57(5). 2019, DOI: 10.1016/j.im.2019.103229.

[45] D.A. Plecher, M. Wandinger, and G. Klinker, "Mixed Reality for Cultural Heritage", in IEEE Conference on Virtual Reality and 3D User Interfaces (VR), Osaka, Japan, pp. 1618-1622. DOI: 10.1109/VR.2019.8797846.

[46] M.K. Bekele, and E. Champion, "A Comparison of Immersive Realities and Interaction Methods: Cultural Learning in Virtual Heritage", Frontiers in Robotics and AI, 6, 2019, pp. 1-12. DOI: 10.3389/frobt.2019.00091.

[47] P. Fogliaroni, "Mixed Reality for Archeology and Cultural Heritage", in Proceedings of the $2^{\text {nd }}$ Workshop on Computing Techniques for SpatioTemporal Data in Archaeology and Cultural Heritage co-located with 10th International Conference on Geographical Information Science (GIScience 2018), 28 August 2018, Melbourne, Australia, pp. 13-19.

[48] S. Rokhsaritalemi, A. Sadeghi-Niaraki, and S-M. Choi, "A Review on Mixed Reality: Current Trends, Challenges and Prospects", Applied Sciences, 10(2), 2020, 26 pages. DOI: 10.3390/app10020636.

[49] O.M. Machidon, M. Duguleana, and M. Carrozzino, "Virtual Humans in Cultural Heritage ICT Applications: A review", Journal of Cultural Heritage, 33, 2018, pp. 249-260. DOI: 10.1016/j.culher.2018.01.007.

[50] F. Škola, S. Rizvic', M. Cozza, L. Barbieri, F. Bruno, D. Skarlatos, and F. Liarokapis, "Virtual Reality with 360-video Storytelling in Cultural Heritage: Study of Presence, Engagement, and Immersion". Sensors $2020, \quad 20, \quad 5851, \quad 2020, \quad 17$ pages. DOI: $10.3390 / \mathrm{s} 2020585$. 